\title{
New detector tube for the detection of nitrite in water
}

\author{
Vladimír Pitschmanna, Zbyněk Kobliha ${ }^{\mathrm{b}}$, Ivana Tušarováa , David Vetchýc \\ ${ }^{a}$ Oritest spol. s r.o., Staropramenná 17, 15000 Praha, Czech Republic \\ ${ }^{b}$ NBC Defence Institute (Vyškov), University of Defence, Kounicova 65, 66200 Brno, Czech Republic \\ ${ }^{c}$ Faculty of Pharmacy, Veterinary and Pharmaceutical University Brno, \\ Palackého 1-3, 61200 Brno, Czech Republic \\ pitschmann@oritest.cz
}

\begin{abstract}
A new colorimetric detector tube for the detection of trace concentrations of nitrite in water was developed. The detector tube is based on a diazo coupling reaction of nitrite with dapsone and N-(1-naphthyl) ethylenediamine dihydrochloride during the formation of red-violet azo dye. Spherical granules (pellets) made from the composite material were used as the carrier of chemical reagents. They were prepared by pelletizing the mixture of microcrystalline cellulose, lactose, kaolin and polyvinylpyrrolidone. Colouring is done on a layer of silica gel impregnated with citric acid. The detector tube is highly sensitive, selective and stable when stored. The detection limit is $0.1 \mu \mathrm{g} \cdot \mathrm{ml}^{-1}$, i.e. $0.03 \mu \mathrm{g} \cdot \mathrm{ml}^{-1} \mathrm{~N}\left(\mathrm{NO}_{2}{ }^{-}\right)$. The optimal measuring range of nitrite concentration in the analyzed sample ranges from 0.5 to $80 \mu \mathrm{g} \cdot \mathrm{ml}^{-1}$, i.e. $0.15-24.36 \mu \mathrm{g} \cdot \mathrm{ml}^{-1} \mathrm{~N}\left(\mathrm{NO}_{2}^{-}\right)$. The detector tube can easily be structurally modified for analysis of nitrates with a detection limit of $1 \mu \mathrm{g} / \mathrm{ml}^{-1}$, i.e. $0.23 \mu$ g. $\mathrm{ml}^{-1} \mathrm{~N}\left(\mathrm{NO}_{3}{ }^{-}\right)$.
\end{abstract}

Keywords: detector tube, composite carrier, dapsone, N-(1-naphthyl) ethylenediamine dihydrochloride

\section{Introduction}

Nitrites are dangerous toxic components in natural waters, which usually occur during a biochemical reduction of nitrate or biochemical oxidation of ammonia nitrogen; therefore, nitrites belong among the most important indicators of faecal contamination of water (bacterial activity). Their high concentrations may also indicate industrial pollution. Nitrites can react in water with the secondary and tertiary amines to form nitrosamines, which are suspected of having carcinogenic effects. Nitrites themselves transform the red blood pigment hemoglobin to methemoglobin which is unable to carry oxygen. Determination of nitrite is therefore significant in terms of environmental and human health protection (Moorcroft et al. 2001, Gray 2008).

The analytical practice uses methods for determination of nitrites that, for example, are based on gas chromatography - mass spectrometry (Kage et al. 2002), electrochemistry (Davis and Compton 2000, Zhang et al. 2009), chemiluminescence (Amini et al. 2005), fluorometry (Jie et al. 1993) or Raman spectrometry (Ianoul et al. 2002). Although these methods are sensitive and accurate, they have many limitations, such as a difficulty of execution or time and cost demands. For these reasons the usage of conventional spectrophotometric methods is in progress (Gürkan et al. 2010, Moldavan 2012, Rastegarzadeh and Kalantaripour 2012), especially the methods based on diazo-coupling reactions according to Griess (Griess 1879). Many diazotizing substances and coupling agents based on aromatic amines and phenols have been tested for these purposes (Saltzman 1954, Szekely 1968, Toei and Mitose 1977, Baveja and Gupta 1983, Norwitz and Keliher 1984, Flamerz and Bashir 1985, Revanasiddappa and Bila 2001, Nagaraja et al. 2001, Afkhani et al. 2004, Cherian and Narayana 2006, Parmar et al. 2008, Veena and Narayana 2009). A variety of test strips for the detection of nitrite in water (Ostrovskaya et al. 2008, Capitán-Vallvey et al. 2001, Amelin and Kolodkin 2001) using the diazo-coupling reactions have been designed. Different test strips are widely used in checking the purity of natural and waste waters or find their use as diagnostic methods in medicine. The disadvantage of test strips is their low robustness, i.e. a difficulty in handling when protective means (such as during emergencies) are used. In these cases, it is preferable to use detector tubes filled with indicator reagents. As an example, a mixture of sulphanilic acid, chromotropic acid and citric acid can be used as the reagent (Zolotov et al. 2002).

The purpose of this paper is to describe the preparation, basic properties and the usage of the newly developed detector tube to monitor nitrite in water. This detector tube is based on the familiar reaction with dapsone and $\mathrm{N}$-(1-naphthyl)ethylenediamine dihydrochloride (Nagaraja et al. 2001), which are fed on the composite carrier of microcrystalline cellulose/lactose/kaolin/polyvinylpyrrolidone. The coloration occurs on the indicator layer of silica gel impregnated with citric acid. The design 
of the detector tube is part of the long-term strategy for the development of simple devices used for the analysis of toxic substances in the field during conditions of environmental and industrial accidents or emergency situations.

\section{Experimental}

\section{Chemicals and apparatus}

The following chemicals were used to prepare the filling of the detector tube: Avicel PH101 microcrystalline cellulose, Avicel RC581 microcrystalline cellulose (FMC BioPolymers, Ireland), 100M Pharmatose lactose (DFE Pharma, Germany), Kollidon $90 \mathrm{~F}$ polyvinylpyrrolidone (BASF, Germany), silica gel (Grace, Germany), kaolin, bis(4-aminophenyl) sulphone (dapsone), N-(1-naphthyl)ethylenediamine dihydrochloride (NEDD), citric acid, acetone (all Sigma-Aldrich, analytical grade), anhydrous ethanol (Riedel de Haën) and doubly distilled water. The composite carrier was prepared using the Stephan UMC 5 homogenizer (Stephan, Germany), a singleblade axial extruder and Pharmex $35 \mathrm{~T}$ spheronizer (Wyss-Probst, Germany). Glass container tubes with an inner diameter of $5 \mathrm{~mm}$ were used as the body of the detector tube, completed by the polyethylene sealing, distributing corpuscles and polyamide nets (Tejas, Czech Republic).

For the development and testing of the detector tube, a standard sodium nitrite (Sigma-Aldrich, analytical grade) was used. Commercial Merckoquant test strips/nitrite $0.5-10 \mathrm{mg} \cdot \mathrm{l}^{-1}$ (Merck, Germany) and Quantofix/Nitrite 1-80 mg. $\mathrm{l}^{-1}$ (Macherey-Nagel, Germany) were applied in order to validate the results.

\section{Preparation of the composite carrier}

The powder mixture of microcrystalline cellulose, lactose, kaolin and polyvinylpyrrolidone was homogenized in a high-speed mixer at the speed of $1000 \mathrm{rpm}$ for 5 minutes. The mixture was moistened with water and injected into the extruder with a barrier (hole diameter $1.25 \mathrm{~mm}$, thickness $1.00 \mathrm{~mm}$ ). Extrusion at the speed of 110 revolutions per minute continued for 10 minutes. The extrudate captured into a bowl was placed on the running spheronization plate in the spheronizer with the hatched pattern where the grid size was $1.0 \mathrm{~mm}$ and the grids were $2.0 \mathrm{~mm}$ apart. Spheronization at the speed of $1000 \mathrm{rpm}$ continued for $10 \mathrm{mi}$ nutes. The resulting pellets were dried at $80{ }^{\circ} \mathrm{C}$ for 20 hours. Physical parameters of the carrier (sieve analysis, pycnometric density, hardness, etc.) were determined by standard procedures (Rabišková et al. 2007).

\section{Preparation of the detector tube}

The composite carrier of microcrystalline cellulose/lactose/kaolin/polyvinylpyrrolidone was impregnated with a solution that contained $2.5 \%$ of dapsone and $0.5 \%$ of NEDD in the mixture of ethanol-acetone $(1: 1)$. One hundred grams of the carrier consumed $20 \mathrm{ml}$ of the impregnation solution. The mixture was air-dried to the loose state.

To prepare the indicator filling, silica gel particles ranging from 0.7 to $0.9 \mathrm{~mm}$ were used; they were cleaned with diluted hydrochloric acid, washed in water to the neutral $\mathrm{pH}$ and activated at a temperature of $130{ }^{\circ} \mathrm{C}$. The $100 \mathrm{~g}$ sample of this modified silica gel was impregnated with $100 \mathrm{ml}$ of the $0.7 \%$ aqueous solution of citric acid and was dried at a temperature of $60-80{ }^{\circ} \mathrm{C}$ until the residual humidity decreased to $10 \%$.

At the beginning, the glass container tube was filled with the indicator layer (silica gel) $10 \mathrm{~mm}$ thick and after that was filled with the composite carrier in a thickness of $100 \mathrm{~mm}$. Both fillings were separated by the net made of polyamide fabric. The fillings were secured against movement by the distributing polyethylene asterisks and by the polyamide nets. The glass tube was sealed at both ends.

\section{Testing of detector tubes and a method of evaluation} The detector tube was opened by breaking both points and was submerged in the examined liquid sample, the indicator filling end pointing downward. The indicator and composite filling were saturated by the examined water samples (Fig. 1). After 1 minute, the liquid from the composite carrier was shaken down on the indication layer so that reagents were washed on that layer. After another 4 minutes, the change in the colour of the indication layer was visually evaluated (in daylight conditions). Using the Pantone Colour Matching System, the obtained data was used to create the etalon of the colour dependency on the nitrite concentration. This etalon was also used for the development of application methods in real conditions. The detection limit was determined as the lowest concentration of nitrites, during which the colour change of the indication layer in the detector tube was visually perceptible (Ostrovskaya et al. 2004, Ostrovskaya et al. 2008). The detection limit was determined by measuring the series of 20 samples for a given concentration level of probability $\mathrm{P}=0.05$ (95\% confirmation of concentration). The determination limit was determined as five times the detection limit. The upper range limit corresponds with the maximum concentration of nitrites, which can still be visually distinguished. 


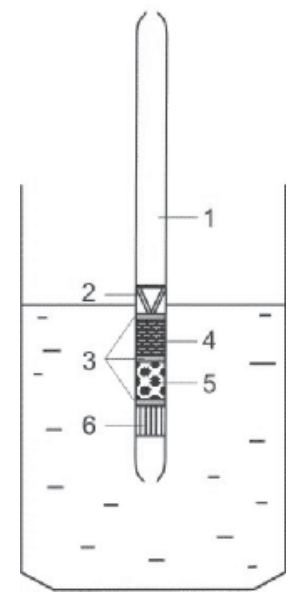

a)

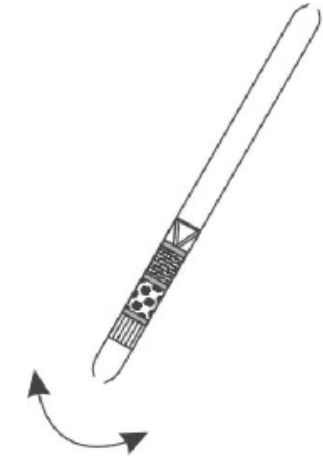

b)
Fig. 1. Scheme design and use of the detector tube: a) application of the detector tube, and its construction ( 1 - glass body, $2-\mathrm{PE}$ conical asterisk, 3 - polyamide net, 4 - composite layer,

5 - indication layer, $6-\mathrm{PE}$ asterisk);

b) liquid from the composite carrier shaken up to indication layer.

\section{Results and discussions}

Composition and properties of the composite carrier Various porous and nonporous materials, such as the reagents carrier (dapsone, NEDD), were studied during the development of the detector tube. In the end, a stable inert composite carrier was selected. In initial studies, several composite materials containing microcrystalline cellulose mixed with $\mathrm{MgO}, \mathrm{TiO}_{2}$, silica gel, aluminium oxide, aluminosilicates of alkali metals, kaolin and a number of polymeric compounds such as polyvinylpyrrolidone, poly(acrylamide-coacrylic acid) potassium salt and poly(methyl vinyl ether-alt-maleic anhydride) were verified. The best results were obtained using microcrystalline cellulose/lactose/kaolin/polyvinylpyrrolidone, which were further investigated. The composite carrier was utilized to construct the detector tube. It contained $31.3 \%$ of Avicel PH101 cellulose, $7.7 \%$ of Avicel RC581 cellulose, $38.0 \%$ of lactose, $19.2 \%$ of kaolin and $3.8 \%$ of polyvinylpyrrolidone. This material exhibited the following parameters: the size of grains (pellets) ranged from 0.8 to $1.25 \mathrm{~mm}$, the pycnometric density was 1.66466 g.cm ${ }^{-3}$ and strength was between

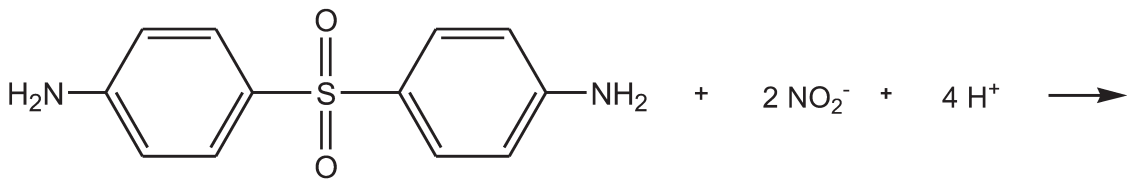<smiles>N#[N+]c1ccc(S(=O)(=O)c2ccc([N+]#N)cc2)cc1</smiles><smiles>NCCNc1cccc2ccccc12</smiles><smiles>NCCNc1ccc(N=Nc2ccc(S(=O)(=O)c3ccc(N=Nc4ccc(NCN)c5ccccc45)cc3)cc2)c2ccccc12</smiles>

Fig. 2. The mechanism of the nitrite reaction with dapsone and NEDD (Nagaraja et al. 2001). 
12.8 to $13.5 \mathrm{~N}$. The material has a greyish colour, it can be poured and compressed well and it does not crumble. The reagents can be washed away from the material using water.

The reaction mechanism and characteristics of colour The developed detector tube is based on the diazo-coupling reaction between nitrites, dapsone and NEDD in an acidic medium that produces red-violet azo dye, probably bis[N-(1-naphthyl) ethylenediamino]-4,4'-diazodiphenylsulphone, with a maximum absorbance of $540 \mathrm{~nm}$. The reaction goes on in two stages. In the first stage, the nitrites react with dapsone in an acidic medium to form the reactive diazonium salt (yellow in colour at higher concentrations). In the second stage (also in the acidic medium), the diazonium salt couples with the NEDD to form the azo dye, which at a temperature of $10-30{ }^{\circ} \mathrm{C}$ is stable for at least 8 hours. The relevant reactions are described in Fig. 2. When detecting the presence of nitrite in water by the detector tube, the silica gel turns into a continuous red-violet colour zone that contrasts well with the original colourless appearance of the filling. (Discoloration occurs even in the composite carrier, but it is brighter and more compact in the silica gel). The reaction is sufficiently fast. The minimum time required for the quantitative reaction course is 5 minutes.

\section{The effect of acidity}

The diazo-coupling reaction takes place only in the presence of acid. The required acidity of the reaction medium is provided by citric acid applied to the indication layer (silica gel). It was found that the highest constant colour intensity is reached when the filling contains citric acid in the concentration range of $0.5-1 \mathrm{~g}$ per $100 \mathrm{~g}$ of silica gel. Lower concentrations of citric acid reduce the colour intensity. A higher content of citric acid has a negative effect on the stability of chromogenic reagents; thus, the colouring may happen even in the absence of nitrites. Satisfactory results were also achieved with some mineral acids $\left(\mathrm{HCl}, \mathrm{HClO}_{4}, \mathrm{H}_{3} \mathrm{PO}_{4}\right)$, but due to the stability of the detector tube filling, citric acid is more suitable.

\section{The effect of reagents and their concentration}

While developing the indication filling, a number of known diazo and coupling reagents (sulphanilic acid, p-aminobenzoic acid, sulfanilamide, p-nitroaniline, $\mathrm{p}$-aminoacetophenone, respectively 1-naphthylamine, NEDD, diphenylamine, iminodibenzyl) and their combinations were investigated. With regard to sensitivity and brilliance of colour combinations, the best results were provided by the combination of dapsone reagents - NEDD. It was found that to achieve the maximum colour effect, one needs 0.3 to $0.6 \mathrm{~g}$ of dapsone, respectively 0.05 to $0.2 \mathrm{~g}$ of NEDD per $100 \mathrm{~g}$ of the composite carrier. Higher concentrations of reagents have no influence on colour intensity and reduce the stability of the filling. Lower concentrations of reagents are reflected in the decline of colour intensity. The theoretical molar ratio of dapsone and NEDD (see the Fig. 2) is approximately 1:2, but during the preparation of the filling, the recommended ratio is approximately $5: 1$.

\section{Analytical data}

The developed detector tube allows the determination of nitrite in water based on visual evaluation of the indicator filling intensity, ranging from 0.5 to $80 \mu \mathrm{g} \cdot \mathrm{ml}^{-1}$, i.e. 0.15 to $24.36 \mu \mathrm{g} \cdot \mathrm{ml}^{-1} \mathrm{~N}\left(\mathrm{NO}_{2}{ }^{-}\right)$ (Table 1). The reproducibility of the method was tested by repeating the analysis of standard nitrite solution during 10 consecutive days. No visually noticeable differences in the results were noted. The detection limit was $0.1 \mu \mathrm{g} \cdot \mathrm{ml}^{-1}$, i.e. $0.03 \mu \mathrm{g} \cdot \mathrm{ml}^{-1}$ $\mathrm{N}\left(\mathrm{NO}_{2}^{-}\right)$.

Tab. 1. Dependence of colour intensity on the concentration of nitrites.

\begin{tabular}{|c|c|c|}
\hline \multirow{2}{*}{$\begin{array}{c}\text { Concentration } \\
\text { of nitrites } \\
\left(\mu \mathrm{g} \cdot \mathrm{ml}^{-1}\right) \\
\end{array}$} & \multicolumn{2}{|c|}{ PANTONE Standard 2006} \\
\hline & Code & Colour composition (\%) \\
\hline 0.5 & $217 \mathrm{U}$ & 3.1 Rub Red, 96.9 Trans Wt \\
\hline 1 & $203 \mathrm{U}$ & $\begin{array}{l}\text { 5. } 5 \text { Rub Red, } 0.8 \text { Yellow, } \\
\text { 93.7 Trans Wt }\end{array}$ \\
\hline 2 & $211 \mathrm{U}$ & $\begin{array}{l}\text { 18.7 Rhod Red, } 6.3 \text { Warm } \\
\text { Red, 75.0 Trans Wt }\end{array}$ \\
\hline 5 & $213 \mathrm{U}$ & $\begin{array}{l}\text { 75.0 Rhod Red, } \\
\text { 25.0 Warm Red }\end{array}$ \\
\hline 10 & $205 \mathrm{U}$ & $\begin{array}{l}43.8 \text { Rub Red, } 6.2 \text { Yellow, } \\
\text { 50.0 Trans. Wt }\end{array}$ \\
\hline 20 & $207 \mathrm{U}$ & $\begin{array}{l}\text { 84.9 Rub Red, } 12.1 \text { Yellow, } \\
\text { 3.0 Black }\end{array}$ \\
\hline 40 & $220 \mathrm{U}$ & 97.0 Rub Red, 3.0 Black \\
\hline 80 & $221 \mathrm{U}$ & 94.1 Rub Red, 5.9 Black \\
\hline
\end{tabular}

\section{The effect of interfering substances}

The effect of various substances normally present in natural and industrial waters was studied during the development of the detector tube. The concentrations of substances that influence the colour effects in the detector tube during the analysis of nitrite were found. The limits of tolerance (the maximum allowable concentration) of certain substances was found at the concentration of $10 \mu \mathrm{g} \cdot \mathrm{ml}^{-1}$ of nitrite are shown in Table 2. From the overview, it is evident that the oxidizing and reducing compounds 
(chlorine, $\mathrm{Fe}^{3+}, \mathrm{SO}_{3}{ }^{2-}, \mathrm{S}^{2-}$ ) significantly interfere. For example, the interfering effect of $\mathrm{Fe}^{3+}$ can be eliminated by impregnating the indication filling with a $1 \%$ solution of ethylenediaminetetraacetic acid (EDTA) sodium salt. The detector tube can be used without water sample preparation if the value of $\mathrm{pH}$ is within the range of $2-13$.

Tab. 2. Limits of tolerance of selected substances during the detection of nitrites with the concentration of $10 \mu \mathrm{g} \cdot \mathrm{ml}^{-1}$

\begin{tabular}{lc}
\hline Foreign compounds & Tolerance limit $\left(\boldsymbol{\mu g} \cdot \mathbf{m l}^{-\mathbf{1}}\right)$ \\
\hline $\mathrm{Chloramine}_{\mathrm{Na}} \mathrm{S}$, & 50 \\
$\mathrm{Na}_{2} \mathrm{SO}_{3}, \mathrm{FeCl}_{3}$ & \\
$\mathrm{CuCl}_{2}, \mathrm{FeSO}_{4}$ & 250 \\
$\mathrm{NaF}$ & 500 \\
$\mathrm{NH}_{4} \mathrm{Cl}$ & 1000 \\
$\mathrm{Na}_{2} \mathrm{SO}_{4}$ & 5000 \\
$\mathrm{NaCl}_{4} \mathrm{NaNO}_{3}$ & 15000 \\
\hline
\end{tabular}

\section{Stability of the filling and detector lifespan}

Stability of the indication filling with silica gel and citric acid is practically unlimited. The composite filling with reagents is stable and can be stored for a long period of time. In a closed flask made of brown glass, it retains its original properties for at least two years. The lifespan of the detector tube is at least as long.

\section{Applications in real samples}

Water samples were collected from various sources, prepared by adding known amounts of nitrites and analyzed by the detector tube in the usual way (as in the samples of nitrites in distilled water). The results were compared with Merckoquant and Quantofix test strips (Table 3). Statistical analysis of results showed no significant differences in accuracy and precision between the proposed method and standard methods.

\section{Applications for the detection of nitrates}

The detector tube design can be modified to perform the analysis of nitrates in water. This modification consists of the fact that a $2 \mathrm{~mm}$ thick layer of granulated zinc (20 mesh, Sigma-Aldrich) is placed between the indication and composite filling. The reaction of zinc with citric acid creates atomic hydrogen, which reduces nitrates to nitrites. The detection limit of determination of nitrate is $1 \mu \mathrm{g} \cdot \mathrm{ml}^{-1}$, i.e. $0.23 \mu \mathrm{g} \cdot \mathrm{ml}^{-1} \mathrm{~N}\left(\mathrm{NO}_{3}^{-}\right)$. The optimum measurement range is 5 to $1000 \mu \mathrm{g} \cdot \mathrm{ml}^{-1}$, i.e. 1.13 to $2.26 \mu \mathrm{g} \cdot \mathrm{ml}^{-1} \mathrm{~N}\left(\mathrm{NO}_{3}^{-}\right)$. The maximum time for the colouring of the indication filling is 10 minutes. The original sensitivity to nitrites in such a modified detector does not change.

\section{Conclusion}

The newly proposed method of semi-quantitative determination of the concentration of nitrites in natural and waste waters using the detector tube is fast, simple, sensitive and selective. The advantage of the proposed detector tube is in its high stability in storage. The detector tube is suitable for the use in the field, especially during environmental and industrial accidents or exceptional emergency situations. Its robust design (unlike the test strips) provides the operator with easy use even when protective gear is used. Comparison of the detector tube with some other methods and means of analysis of nitrites is shown in Table 4. Chemical reagents dapsone and NEDD applied to the composite carrier are stable and, in the presence of citric acid and nitrites, create a strongly coloured reaction product. The detection limit is $0.1 \mu$ g.ml $l^{-1}$, i.e. $0.03 \mu$ g. $\mathrm{ml}^{-1} \mathrm{~N}\left(\mathrm{NO}_{2}^{-}\right)$. The proposed method is reproducible and provides correct analytical results. The analyzed samples do not require any preparation. By inserting a layer of granulated zinc between the indication and composite filling, the detector tube can be easily modified to determine the presence of nitrates in water with a detection limit of $1 \mu \mathrm{g} \cdot \mathrm{ml}^{-1}$, i.e. $0.23 \mu \mathrm{g} . \mathrm{ml}^{-1} \mathrm{~N}\left(\mathrm{NO}_{3}{ }^{-}\right)$.

Further investigation will be focused on increasing the resistance of the detector tube against disturbing effects, more detailed study of its application for the determination of nitrates and assessing the possibility of an objective evaluation of colour

Tab. 3. Detection of nitrites in natural waters compared with test strips.

\begin{tabular}{|c|c|c|c|c|}
\hline \multirow{2}{*}{ Sample } & \multirow{2}{*}{ Nitrites inserted ( $\mu$ g.ml $\left.{ }^{-1}\right)$} & \multicolumn{3}{|c|}{ Nitrites found $\left(\mu \mathrm{g} \cdot \mathrm{ml}^{-1}\right)$} \\
\hline & & Proposed method & Merckoquant strips & Quantofix strips \\
\hline 1 & 1.4 & 1 & 1 & 1 \\
\hline 2 & 2.4 & 2 & 2 & $>1$ \\
\hline 3 & 4.1 & 5 & 5 & 5 \\
\hline 4 & 6.8 & $>5$ & 10 & $<10$ \\
\hline 5 & 9.1 & 10 & 10 & 10 \\
\hline
\end{tabular}


Tab. 4. Comparison of some of the known methods for the determination of nitrites.

\begin{tabular}{lcl}
\hline Method & Detection limit $\left(\boldsymbol{\mu g} \cdot \mathbf{m l}^{-\mathbf{1}}\right)$ & Notes \\
\hline Chemiluminescent & $0.001-0.01$ & Instrumental demand, preparation of a sample \\
Spectrophotometric & $0.005-0.1$ & Instrumentation, preparation of a sample \\
GC/MS & 0.1 & Instrumental demand, high cost \\
Electrochemical & $0.01-0.1$ & Instrumental demand \\
Detection strip & $0.1-1$ & Simple design, terrain analysis \\
Proposed method & 0.1 & Simple design, terrain analysis - high robustness \\
\hline
\end{tabular}

changes with reflective spectrophotometry (tristimulus colorimetry).

\section{Acknowledgement}

This work was supported by the Ministry of Interior of the Czech Republic (research project VG 20102013048), and by the Ministry of Defence of the Czech Republic (project to support development of the organization).

\section{References}

Afkhani A, Masahi S, Bahram M (2004) Bull Korean Chem Soc 25: 1009-1011.

Amelin VG, Kolodkin IS (2001) J Anal Chem 56: 182-187.

Amini MK, Pourhossein M, Talebi M (2005) J Iran Chem Soc 2: 305-314.

Baveja AK, Gupta VK (1983) Int J Environ Anal Chem 14: 193-200.

Capitán-Vallvey LF, Avidad R, Fernández-Ramos MD, Ariza-Avidad A, Arroyo E (2002) Anal Bioanal Chem 373: 289-294.

Cherian T, Narayana B (2006) J Braz Chem Soc 17: $577-581$.

Davis J, Compton RG (2000) Anal Chim Acta 404: 241-247.

Flamerz S, Bashir WA (1985) Analyst 110: 1513-1515.

Gray NF (2008) Drinking Water Quality: Problems and Solutions. University Press, Cambridge.

Griess P (1879) Ber 12: 426-428.

Gürkan R, Ulusoy HI, Akçay M (2010) Eurasian J Anal Chem 5: 16-31.
Ianoul A, Coleman T, Aster SA (2002) Anal Chem 74: 1458-1461.

Jie Kage S, Kudo K, Ikeda N (2002) J Anal Toxicol 26: $320-324$.

Moldavan Z (2012) Bull Chem Soc Ethiop 26: 159-169.

Moorcroft MJ, Davis J, Compton RG (2001) Talanta 54: 785-803.

Nagaraja P, Shivaswamy M, Kumar M (2001) Int J Environ Anal Chem 80: 39-48.

Norwitz G, Keliher PN (1984) Analyst 109: 1281-1286.

Ostrovskaya VM, Reshetnyak EA, Nikitina NA, Panteleimonov AV, Kholin YuV (2004) J Anal Chem 59: 995-1001.

Ostrovskaya VM, Tsygankov AV, Prokopenko OA, Buryak AK, Reshetnyak EA, Nikitina NA (2008) J Anal Chem 63: 792-798.

Parmar P, Marhew SB, Gupta VK, Pillai AK (2008) Acta Chim Slov 55: 236-242.

Rabišková M, Häring A, Minczingerová K, Havlásek M, Musilová P (2007) Chem Listy 101: 70-77.

Rastegarzadeh S, Kalantaripour M (2012) Quim Nova 35: 766-770.

Revanasiddappa KK, Bila M (2001) Mikrochim Acta 137: 249-253.

Saltzman BE (1954) Anal Chem 26: 1949-1955.

Szekely E (1968) Talanta 15: 795-801.

Toei K, Mitose T (1977) Anal Chim Acta 88: 125-129.

Veena K, Narayana B (2009) Indian J Chem Tech 16: 89-92.

Zhang Y, Luo L, Ding Y, Li L (2009) Microchim Acta 167: 123-128.

Zolotov YA, Ivanov VM, Amelin VG (2002) Chemical test methods of analysis. Elsevier, Amsterdam. 